\title{
As utopias da realidade constitucional: nos trilhos do contraponto neoliberal ${ }^{*}$
}

\author{
Eduardo Kroeff Machado Carrion**
}

\section{INTRODUÇÃO}

Começarei minhas observações relembrando uma antiga piada sobre os regimes burocráticos do leste europeu. Alguém viaja para um dos países do leste europeu e, ciente da censura de sua correspondência, avisa para os amigos: "Vamos combinar um código. Se vocês receberem minhas cartas em tinta azul, o que elas disserem será verdade; se estiver em tinta vermelha, será mentira". Algum tempo depois escreve para os amigos em tinta azul: "Tudo aqui é maravilhoso: as condições de vida são as melhores possíveis, a liberdade é plena. A única coisa que não se consegue é encontrar tinta vermelha".

Num certo sentido, essa piada reporta-nos aos limites da linguagem, no nosso caso aos limites da linguagem constitucional. Ou melhor, aos limites da linguagem constitucional no paradigma tradicional. Aliás o título geral do seminário: Crise(s) de Paradigmas e Estado Democrático de Direito: um desvelamento hermenêutico, sugere esse tipo de reflexão. Senão, vejamos.

Quando falamos em Utopias da Realidade Constitucional, defrontamo-nos, no paradigma tradicional, com um impasse, um paradoxo ou mesmo uma contradição. Afinal, utopia reporta-se, na etimologia grega da palavra, a nenhum lugar ou, em uma de suas conotações, a um lugar ideal. Já Constituição, a todo lugar, já que norma fundamental do ordenamento jurídico, ou, também em uma de suas conotações, a um lugar real.

Nessa perspectiva, Lassalle, em sua clássica conferência, distingue entre Constituição real e efetiva, os "fatores reais de poder", e "Constituição formal e jurídica". Em caso de contraste, prevaleceria sempre a primeira em detrimento da segunda, mera "folha de papel".

Na perspectiva do paradigma tradicional, a Constituição seria uma espécie

\footnotetext{
* Texto que serviu de base para a exposição realizada, com esse título, no seminário Crise(s) de Paradigma(s) e Estado Democrático de Direito: Um Des-Velamento Hermenêutico, promovido pelo Instituto de Hermenêutica Jurídica durante o III FSM, Porto Alegre, 25/01/2003. ** Professor Titular de Direito Constitucional e ex-Diretor da Faculdade de Direito da UFRGS.
} 
de vulgata jurídica dos interesses do status quo, sem qualquer veleidade utópica ou transformadora. Tratar-se-ia, finalmente, da vitória do real sobre o ideal.

Essa perspectiva encontra eco na construção teórica tradicional. Quando falamos em Constituição posta, em poderes constituídos, num certo sentido exilamos toda dimensão utópica e transformadora do âmbito do direito constitucional. Uma breve e passageira concessão é feita ao falar-se em poder constituinte originário e em poderes constituintes. Mas sempre sob o olhar atento e sobranceiro dos "fatores reais de poder".

Como escapar da contradição referida do paradigma tradicional? Como encontrar, simbolicamente, a tinta vermelha para escrever a nossa carta?

\section{METALINGUAGEM CONSTITUCIONAL}

Assim como distinguimos entre linguagem, isto é, a linguagem que se fala, e metalinguagem, isto é, a linguagem na qual se fala sobre a linguagem que se fala, podemos também distinguir entre linguagem constitucional, ou seja, a linguagem que se fala na Constituição ou a linguagem que se fala sobre a Constituição, e metalinguagem constitucional, ou seja, a linguagem na qual se fala sobre a linguagem que se fala na Constituição ou na qual se fala sobre a linguagem que se fala sobre a Constituição.
Talvez, assim, consigamos melhor resgatar ou melhor acentuar o que pode existir de dimensão utópica ou de dimensão transformadora mesmo na Constituição posta, mesmo em face dos poderes constituídos. Em outros termos, o ideal pode emergir do real, sem que se estabeleça necessariamente uma contradição, tal como sugerido pelo paradigma tradicional. A esse propósito, gostaria de fazer uma breve referência às denominadas normas programáticas.

\section{AS NORMAS PROGRAMÁTICAS ${ }^{1}$}

Além de normas preceptivas e de normas organizativas ou institutivas, as Constituições contemporâneas contêm, em maior ou menor medida, normas programáticas "através das quais o constituinte, em vez de regular, direta e imediatamente determinados interesses, limitouse a traçar-lhes os princípios para serem cumpridos pelos órgãos (legislativos, executivos, jurisdicionais e administrativos), como programas das respectivas atividades, visando à realização dos fins sociais do Estado."2 Correspondem elas em grande parte à realidade e às exigências do denominado Estado Social, cujos textos constitucionais incorporam inúmeras reivindicações das classes trabalhadoras (o conteúdo social das constituições, expresso sobretudo nas declarações dos direitos econômicos e sociais), no sentido da prática de uma democracia substancial.

\footnotetext{
1 Retomamos aqui algumas observações já formuladas em outro trabalho: CARRION, Eduardo Machado Kroeff. A Dimensão Prospectiva das Constituições. Revista da Ordem dos Advogados do Brasil, Sâo Paulo, n.44, p. 80-87, 1988.
}

2 SILVA, José Afonso da. Aplicabilidade das Normas Constitucionais. 3.ed. rev. e ampl. São Paulo: Malheiros 1998. p. 138. 
Tese tradicional tem negado eficácia jurídica às normas constitucionais programáticas, caracterizando então como programática toda norma constitucional que aponte para a transformação do status quo e para a conquista de novos direitos populares. Entretanto, a melhor doutrina (Pontes de Miranda, entre nós, por exemplo) e jurisprudência (na França e na Itália, desde os anos 50) têm reconhecido eficácia vinculativa ou positividade jurídico-constitucional (as expressões são de Canotilho) às normas constitucionais programáticas. Questão distinta, a da aplicação direta das normas constitucionais respeitantes aos direitos fundamentais (basicamente os direitos individuais e políticos, tanto os clássicos e os tradicionais como os novos) e não propriamente com relação às normas programáticas.

Qual finalmente a eficácia vinculativa ou a positividade jurídico-constitucional das normas programáticas? Em primeiro lugar, obrigam o legislador ordinário a legislar no sentido do mandamento da norma programática. Aqui, a importância da ação de inconstitucionalidade por omissão e do mandado de injunção e a necessidade de a classe trabalhadora não limitar sua luta por uma legislação econômica e social mais avançada apenas ao plano constitucional. Vinculação não apenas do legislador ordinário, mas também dos demais órgãos do Estado (Executivo e Judiciário). Demais, possuem eficácia interpretativa, além de gerarem verdadeiros direitos subjetivos, pelo menos em seu aspecto negativo, para os cidadãos.
Lassalle colaborou decisivamente, numa obra clássica, para que se entendesse a Constituição formal ou jurídica (a "folha de papel") como mero reflexo, simples epifenômeno da Constituição real e efetiva (os "fatores reais de poder"). Embora a conexão com a realidade seja um pressuposto da força normativa da Constituição formal ou jurídica, esta não é um simples reflexo das condições sociais, mas, devido a seu caráter normativo, pretende também, por sua vez, conformar a realidade. Aquele entendimento, levado às últimas conseqüências, conduz à afirmação da existência de uma oposição insuperável entre programa que fala no que ainda não existe e que deve ser obtido e conquistado no futuro, e Constituição que, pelo contrário, deve falar no que já existe e que já foi obtido e conquistado no momento presente (Stalin, por ocasião da discussão do projeto de Constituição para a URSS, em 1936).

O equívoco político da crítica à importância das normas constitucionais programáticas se revela melhor nas próprias palavras de um de seus mais competentes e autorizados intérpretes no Brasil: "A Constituição, para que não seja uma mentira e possa ser respeitada e acatada, há de contemplar tão-somente direitos que possam ser imediata e prontamente fruídos pela sociedade"; "nela (os constituintes) não deverão incluir senão acenos para o que o nosso modelo de organização social permita que a sociedade obtenha e, mais do que isso, senão para o de que, socialmente, estejam as forças dominantes dispostas a abrir mão em favor dos vinte e cinco milhões."3

3 GRAU, Eros Roberto. A Constituinte e a Constituição que Teremos. São Paulo: Revista dos Tribunais, 1985. p .46-47. 
Este aparente realismo político torna a Constituição em última análise inútil para as classes trabalhadoras. Se devemos criticar a hipocrisia constitucional representada pela revogação, muitas vezes, da Constituição formal ou jurídica pela Constituição real e efetiva, não podemos desconhecer a dimensão prospectiva da Constituição formal ou jurídica, apontando para um horizonte histórico mais avançado. Em outros termos, a Constituição formal ou jurídica não deve ser um obstáculo, mas um instrumento para o progresso da Constituição real e efetiva.

Nas democracias liberais, as Constituições costumam representar um compromisso entre tendências conservadoras e tendências reformadoras, entre o passado da democracia meramente formal e o futuro da democracia substancial. A realidade destas Constituições reflete em grande parte a própria dinâmica da democracia liberal. Em que pese as origens aristocráticas dela, a resistência e a organização populares possibilitaram efetivas conquistas que vieram a significar um real alargamento da prática democrática no interior da democracia liberal. Numa certa medida, os espaços democráticos existentes na democracia liberal foram sobretudo resultado da luta da classe trabalhadora, constituindo-se então como autênticos direitos populares. A democracia liberal caracteriza-se assim como uma relação de forças políticas, correspondendo parcialmente também às reivindicações dos explorados e dos dominados, ainda que nos parâmetros da ordem estabelecida. Em outros termos, a democracia liberal, como prática histórica da democracia, assinala-se como um processo dinâmico cujo resultado, sempre provisório, esta além do horizonte político das classes dominantes, embora esteja aquém do horizonte político da classe trabalhadora.

O embate entre tendências conservadoras e tendências reformadoras tem como resultado a incorporação, nas modernas Constituições, de inúmeras normas concernentes aos direitos sociais, à organização da economia, à participação dos cidadãos, ao controle da administração. Como consequiência de uma relação de forças políticas ainda desfavorável à classe trabalhadora, estas normas nem sempre desenvolvem força jurídica suficiente para impor-se de imediato na integralidade do seu mandamento legal. Expressam não só o ideário social da época, mas muitas vezes uma concessão apenas em princípio por parte das classes dominantes, remetendo portanto a uma decisão política ulterior o problema de sua integralização ou não. Trata-se aqui, do que se convencionou denominar na literatura jurídica de normas programáticas, se bem com uma certa impropriedade, já que possuem de qualquer maneira, como se viu, eficácia vinculativa, nos limites de sua eficácia é verdade. Ao mesmo tempo em que cumprem uma função legitimadora da ordem estabelecida, assumem também uma função prospectiva, apontando para o aperfeiçoamento ou mesmo a superação desta ordem. Neste sentido, Piero Calamandrei referia-se às Constituições modernas como "uma polêmica contra o passado e um programa de reformas em direção ao futuro". 


\section{PROBLEMAS}

Gostaria ainda de chamar a atenção para dois problemas lembrados por $\mathrm{Vi}$ tal Moreira ${ }^{4}$ e relacionados com o tema em exame. Primeiro, o dos excessos programáticos da Constituição, e, segundo, o do excesso de Constituição.

Os excessos programáticos da Constituição, refletindo um excessivo voluntarismo político, podem revelar-se contraproducentes para a capacidade regulatória da Constituição, convertendo-se finalmente em um déficit de Constituição.

Por sua vez, o excesso de Constituição, além de poder limitar demasiadamente a liberdade da maioria de cada momento, atingindo o princípio democrático, pode contraditoriamente acabar em um déficit de normatividade dos preceitos constitucionais. Como salienta o constitucionalista, paradoxalmente, quanto mais Constituição menos Constituição.

\section{CONCLUSÃO}

Caberia por fim uma palavra com relação ao neoliberalismo. O neoliberalismo avilta a dimensão prospectiva das Constituições, exila ainda mais toda dimensão utópica e transformadora do âmbito do direito constitucional.

Desde os primórdios do capitalismo, o Estado exerceu um papel decisivo na reprodução do capital, inclusive inter- vindo diretamente no plano da produção e não apenas no da circulação de mercadorias. No Brasil, em particular, a função do Estado como agente econômico tem sido bastante acentuada. Nosso padrão de desenvolvimento capitalista nunca prescindiu da intervenção vigorosa e incisiva do Estado. Alguns referem-se mesmo à figura sui generis de um "capitalismo sem capital", isto é de um capitalismo gestado com recursos públicos. Aqui, com maior razão talvez, o Estado produziu num certo sentido os produtores. Neste contexto, cabe indagar-se sobre o significado do neoliberalismo econômico, emergente sobretudo a partir dos anos 70 , numa conjuntura de crise econômica do sistema capitalista. Neoliberalismo este que funda na crítica ao Estado e na apologia do mercado livre seu programa de luta. Até que ponto a contrapartida necessária do neoliberalismo econômico não seria o conservadorismo político? Para tentar responder a estas e a outras questões, convém inicialmente examinar algumas das características do Estado contemporâneo.

Sob o impacto de profundas transformações nas esferas econômica, política e social, desde o final do século passado, a concepção tradicional do Estado, percebido antes de tudo pela idéia de autoridade, passa, pouco a pouco, a ser contestada. A noção de um Estado norteado pelo conceito de ser-

\footnotetext{
4 MOREIRA, Vital, Constituição e Democracia na Experiência Portuguesa. In: CONSTITUIÇÃO e Democracia. São Paulo: Max Limonad, 2001. p. 270-273.

5 Retomamos aqui observações já formuladas em outro trabalho: CARRION, Eduardo Kroeff Machado. Neoliberalismo x Estado Social. In: . Apontamentos de Direito Constitucional. Porto Alegre: Livraria do Advogado, 1997. p. 155-158.
} 
viço público toma assim o lugar da imagem de um Estado-poder de dominação da doutrina jurídica alemã ou de um Estado-soberania da correspondente teoria jurídica francesa. Estado este que se definiria antes pela prestação de serviços do que por manifestações de autoridade. Por um lado, o Estado pretende não só coordenar e orientar, quando não direcionar, a atividade da iniciativa privada, como também se substituir, em certas áreas estratégicas, à própria iniciativa privada, de forma a controlar e a regular as flutuações da economia capitalista; por outro, o Estado procura intervir nas relações sociais, contrapondo às desigualdades de fato uma política social compensatória, com o objetivo de evitar ou abrandar tensões que pudessem eventualmente colocar em risco o sistema.

Ao Estado liberal anterior correspondiam princípios econômicos como o da liberdade da indústria e do comércio e o da igualdade de tratamento em matéria econômica, impedindo assim medidas discriminatórias ou seletivas por parte da administração com relação à atividade da iniciativa privada. Com a mudança da natureza do Estado, novos princípios econômicos surgem, refletidos em expressões como "planejamento econômico"; "estatizações"; "democracia econômica e social", em complemento à democracia política, etc. Novos princípios econômicos estes que, sobretudo após a Segunda Guerra Mundial, encontraram acolhida cada vez maior nas Constituições, recebendo então estatuto e garantia constitucionais. Estes novos princípios econômicos apresentam inspiração distinta daqueles clássicos. Ao invés de significar uma limitação à ação do Estado, implicam numa maior intervenção do Estado.

O Estado Social, que resultou desta nova realidade, correspondeu em grande parte a um pacto social-democrata entre capitalistas e trabalhadores, numa fase de expansão da economia capitalista, desde o início dos anos 40 até o final dos anos 60. Face à crise econômica do sistema capitalista, a partir do final dos anos 60 , inicialmente sob a modalidade de uma crise financeira, o Estado Social encontra-se igualmente em crise. Neste quadro, a política econômica neoliberal expressa também a tentativa de retroceder com relação às conquistas da fase anterior de expansão da economia capitalista.

Os neoliberais acreditam na superioridade da regulação pelo mercado, o intervencionismo estatal, representando assim um fator de transtorno e de desajustamento da economia de mercado. Entretanto, esta apologia do mercado livre não seria uma maneira de mascarar uma investida do capital contra as conquistas históricas da classe trabalhadora, expressas no pacto social-democrata do Estado Social? Liberar a empresa não seria na realidade uma forma de liberar a empresa de suas funções sociais e de desarmar a classe trabalhadora frente a esta nova ofensiva do capital, regredindo a economia a uma fase já superada? Aliás, a proposta neoliberal não é incompatível com a defesa de uma política de subvenções e de transferência de recursos do Estado para o setor privado, o mercado livre funcionando apenas ou prioritariamente a nível das relações de trabalho. Face à crise econômica, ao invés de preconizar uma política econômica de cres- 
cimento em benefício da sociedade, ela sustenta uma política econômica de recessão e de austeridade em defesa do lucro. O mais grave parece ser o fato de esta maior liberdade econômica propugnada não se traduzir em uma ampliação das liberdades públicas. O neoliberalismo coaduna-se perfeitamente com um Estado forte e autoritário, significando em última análise uma subordinação da política do Estado aos interesses exclusivos da empresa privada.

Gostaria de terminar minha intervenção, lembrando uma vez mais a magistral lição de Juan Bautista Alberdi, pai da Constituição argentina de 1853, para quem há Constituições de criação e Constituições de conservação, a América Latina necessitando das primeiras, isto é, daquelas que sirvam de instrumento para a construção de uma sociedade democrática e moderna.

\section{REFERÊNCIAS}

CARRION, Eduardo Machado Kroeff. A Dimensão Prospectiva das Constituições. Revista da Ordem dos Advogados do Brasil, São Paulo, n.44, p. 80-87, 1988.

. Neoliberalismo x Estado Social. In:__. Apontamentos de Direito Constitucional. Porto Alegre: Livraria do Advogado, 1997. p. 155-158.

GRAU, Eros Roberto. A Constituinte e a Constituição que Teremos. São Paulo: Editora Revista dos Tribunais, 1985.

MOREIRA, Vital. Constituição e Democracia na Experiência Portuguesa. In CONSTITUIÇÃO e Democracia. São Paulo: Editora Max Limonad, 2001.

SILVA, José Afonso da. Aplicabilidade das Normas Constitucionais. São Paulo: Malheiros Editores Ltda., 1998, $3^{a}$ edição, revista, ampliada e atualizada. 
